
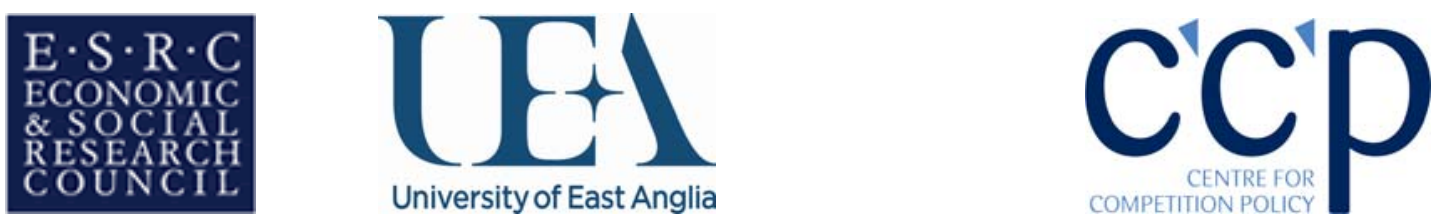

\title{
Modelling international wind energy diffusion: Are the patterns of induced diffusion ' $S$ ' shaped?
}

\author{
Ivan Diaz-Rainey* \\ Norwich Business School \& ESRC Centre for Competition Policy, \\ University of East Anglia, Norwich, UK \\ CCP Working Paper 10-7
}

\begin{abstract}
:
Recent years have seen growing academic interest in the concept of induced diffusion as efforts to address concerns about energy security and climate change have intensified. Research on induced diffusion explores whether policy tools or interventions can incentivise the diffusion of innovations. This body of knowledge has explored the effectiveness and efficiency of various policy interventions and as such has been concerned with the determinants of diffusion. This paper is, by way of contrast, concerned with the patterns of diffusion when diffusion is induced. Thus, using two datasets, the paper explores the patterns of international wind energy diffusion in OECD countries. The model employed in the paper predicted that wind energy, as a complex and expensive innovation, would exhibit the characteristics of a logistic diffusion curve rather than a loglogistic curve. The empirical modelling of these two curves shows that, consistent with a further proposition developed in the paper, the results are no way near as conclusive as those of earlier studies. These results imply that the patterns of induced diffusion are considerably different to those observed conventionally.

January 2010
\end{abstract}

JEL Codes: O33, O38, Q28, Q58, H23.

Key words: diffusion, induced diffusion, energy policy. 
Acknowledgements: Some of the work on this paper was undertaken while I was a Jean Monnet Fellow at the Robert Schuman Centre for Advanced Studies, European University Institute. I would like to thank Steve Davies, Gordon MacKerron and Catherine Waddams for helpful suggestions. Lorcan Lyons (IEA) and Birger T. Madsen (BTM Consult) provided invaluable assistance with respect to the datasets. The paper has benefited from comments received during presentations at the ESRC CCP Seminar Series (2005, Norwich), the 31st IAEE Conference (2008, Istanbul), the 4th ENERDAY Conference (2009, Dresden) and the UEA Energy Seminar Series (2009, Norwich). The usual disclaimer applies. The support of the Economic and Social Research Council is gratefully acknowledged.

\section{Contact Details:}

Norwich Business School, University of East Anglia, Norwich, UK, NR4 7TJ; Telephone + 44 (0)1603 597182; Fax: 44 (0)1603 593343; Email: I.Diazrainey@uea.ac.uk 


\section{Introduction}

Recent years have seen growing academic interest in the concept of induced diffusion as efforts to address concerns about energy security and climate change have intensified (see Jaffe et al. 2002; Montalvo and Kemp 2008). Research on induced diffusion explores whether policy tools or interventions can incentivise the diffusion of, inter alia, environmental innovations. This body of knowledge has explored the effectiveness and efficiency of various policy interventions and as such has been concerned with the determinants of diffusion. This paper is, by way of contrast, concerned with the patterns of diffusion when it is induced. ${ }^{1}$ The paper, therefore, explores the question of whether the patterns of induced diffusion are different to the conventional ' $S$ ' shaped patterns observed when diffusion is unaffected by policy interventions. This is done by testing Davies' (1979) innovation diffusion model in the context of the international diffusion of wind energy. The reasons for the focus are multiple and are explored in more detail below.

\subsection{The Induced Diffusion Literature}

Jaffe et al. (2002, p.49) explain the concern with induced diffusion, as distinct to induced innovation, when they observe that

"While the induced innovation literature focuses on the potential for environmental policy to bring forth new technology through innovation, there is also a widely-held view that significant reductions in environmental impacts could be achieved through more widespread diffusion of existing economicallyattractive technologies."

Following on from this Diaz-Rainey $(2008$, p.27) suggests a more formal definition of induced diffusion as: Any intervention that aims to alter the speed and/or total level of adoption of an innovation by directly or indirectly internalising positive and/or negative externalities. There is no reason why interventions to induce diffusion are solely the preserve of regulated industries (such as former state monopolies) but the current context is inspired by such a case, namely, electricity generation. Indeed, regulated

\footnotetext{
${ }^{1}$ There are various traditions in diffusion research (Rogers 1995), however, the concern with the patterns of diffusion has been dominated by those researching diffusion from a neoclassical economics tradition (Lissoni and Metcalfe 1994)
} 
industries are of particular interest since economic regulation plays a major role in determining investment choices and, by extension, technology choices. More generally, a gap has been identified in the induced diffusion literature in terms of understanding the patterns of induced diffusion (Diaz-Rainey 2008).

Examining the patterns of wind diffusion allows us to test established theory, Davies' (1979) model of innovation diffusion, in the context of induced diffusion. This poses a number of interesting questions. For example, even though wind energy is on a cost basis in the same order of magnitude as incumbent electricity generation technologies, for it to diffuse, externalities such as pollutants generally need to be internalised into the prevailing regulatory regime (see Section 1.2.). Hence, if wind diffusion requires the internalisation of externalities, then it is not a 'natural'/unfettered market process, so does this in turn alter the pattern of innovation diffusion? The a priori expectation is that differences will emerge. It is conceivable that, due to policy reversals as part of the political cycle, the pattern of diffusion may not be as smooth under induced diffusion as compared to when interventions play no part in the diffusion process (see Section 2).

If the patterns of induced diffusion are found to be considerably different to when there are no policy interventions this would imply that policies to induce diffusion do work. This in turn would contrast with assertions by some that interventions have little or no impact on diffusion (Stoneman 2002) and would be broadly in line with the preponderance of the evidence that diffusion can be induced (Jaffe et al. 2002).

\subsection{Wind Energy and Energy Policy}

As the most viable large scale 'new' renewable generating technology, wind energy is at the centre of the energy policy debate in a large number of countries. Proponents of wind energy argue that it offers the potential to meet environmental goals, such as those of the Kyoto Protocol, while at the same time helping to assuage security of supply concerns by reducing reliance on imported fossil fuels from unstable regions of the world. Detractors of wind energy point to a myriad of issues to argue that its wide spread diffusion will run counter to energy policy goals of having 
affordable and secure energy supplies. These include: intermittency, low load factor, high cost, visual intrusion, noise disturbance and concerns about the public's acceptance of projects, such as 'Not In My Backyard' (NIMBY) objections.

Figure 1: Generating capacity of turbines and generating costs per unit

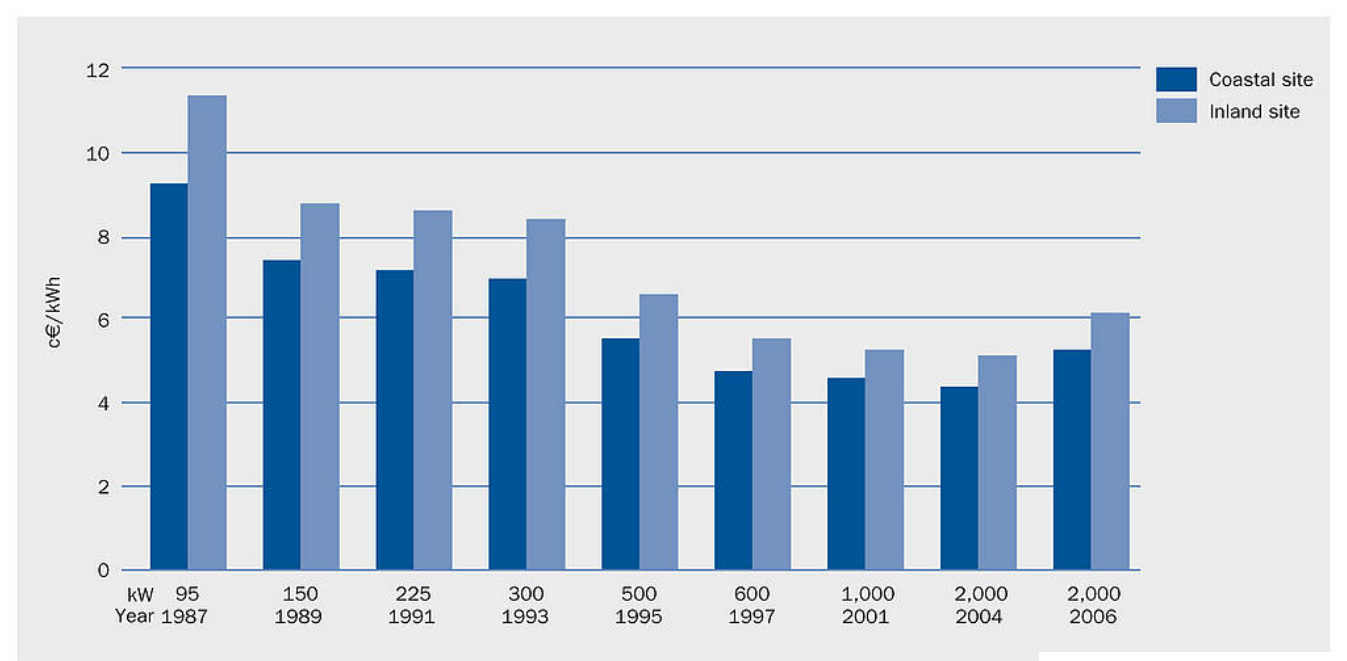

Source: Riso DTU (Cited in EWEA 2009a, p.210).

Note: Figure relates to cost of wind power generation in Denmark

There is a great deal of evidence showing that even before accounting for diversification effects (Awerbuch 2000: 2006), energy security concerns and environmental externalities, wind generation, on a cost basis, has been over the past decade in the same order of magnitude as more conventional generating technologies (Anderson 2007; Dale et al. 2004). Indeed, the cost of electricity generation from wind energy has declined dramatically over the last few decades (Figure 1). There are numerous factors for this cost decline including:

- Scale economies: Substantial economies of scale have been derived from ever larger turbines. Turbines in the 1980 s tended to be 15 meters tall whereas by 2006 they had reached up to 150 meters in size (EWEA 2009a). Figure 1 shows the effect of larger turbines in Denmark has been to increase the generating capacity of individual turbines twenty fold between 1987 and 2006. 
- Technological advances: There have been considerable technological advances in a range of areas including materials and blade and generator design (EWEA 2009a). These developments have played an important role in enabling ever larger and more efficient turbines (Figure 1).

- 'Learning By Doing': Numerous studies have shown that 'learning by doing' has also played an important role in these cost reductions with most studies reporting progress ratios between 80 per cent and 95 per cent (see McDonald and Schrattenholzer 2001 and Junginger et al. 2005 for a summary).

The decreasing cost of electricity generating from wind energy, as well as higher fossil fuel prices from around 2003 onwards have made wind energy increasingly competitive with the most economic forms of generation (gas or coal). As a result wind energy is increasingly seen as a cost effective alternative. For instance, Dale et al. (2004) estimate that having 20 per cent of generation from wind energy in the UK would add 5 per cent to the average electricity bill.

Despite the improved cost performance of wind energy relative to other generating technologies, it is broadly acknowledged that for wind energy to diffuse environmental externalities, most notably $\mathrm{CO} 2$, still need to be internalised so as to induce diffusion. Accordingly a whole range of policies have been developed to provide investment support for renewable energy projects, including the EU Emission Trading Scheme, tax breaks, the Kyoto Clean Development Mechanisms, Feed In Tariffs (FIT) and Green Certificates Markets (GCM). There has been a good deal of debate about the efficacy and efficiency of the two main policy options used in practice to support renewables investment, namely FIT and GCM (see Agnolucci 2007 and Kildegaard 2008 for reviews). In this debate surprisingly few contributions have been framed around a neoclassical economics diffusion framework. One exception is Soderholm and Klaassen (2007). They found that large levels of wind energy deployment in Denmark, Germany and Spain has been associated with FITs and reductions in investment costs that are in turn explained by learning activities and public support for R\&D. 
The increasingly favourable cost attributes of wind energy, rising fossil fuel prices and heightened concern about global warming and energy security mean that wind energy is growing into a substantial industry. Up to recent years the industry has been dominated by European manufacturers such as Vestas, Gamesa, Enercon and Siemens, reflecting the fact the preponderance of the diffusion of wind energy had happened in Europe. In 2002 European manufacturers accounted for approximately 90 per cent of the capacity sold worldwide (EWEA 2003, p.125). Further, Beise and Rennings (2005, p.14) observe that the 'lead market' effect of the early use of strict regulations (FIT) in Denmark meant that high wind energy penetration rates translated into industrial policy benefits, namely; a large export market in wind turbines. The last few years have, however, seen the turbine manufacturers from other parts of the world, most notably GE Energy from the US, Suzlon Energy from India and Goldwind from China, becoming increasingly important in the sector. This trend reflects a rapid acceleration of wind energy diffusion in the rest of the world, with approximately equal amounts of wind energy being installed in 2008 in Asia (8,579MW), Europe (8,877MW) and North America (8,884MW) (GWEC 2009).

To summarise, this paper explores the patterns of induced diffusion in the context of the international diffusion of wind energy. The remainder of the paper is structured as follows. Section 2 outlines the theoretical framework including the model used. Section 3 discusses research design and the data used, while Section 4 reports the results of the econometric modelling. Section 5 contains concluding remarks.

\section{Theoretical model}

"It became obvious that the observations are not points of equilibrium which may or may not change over time, but points on an adjustment path, moving more or less consistently towards a new equilibrium position. Hence we should phrase our questions in terms of the beginning of the movement, its rate and its destination." Griliches (1957, p.503)

The late 1950s and early 1960s witnessed the entry of economists into the sphere of diffusion research. A prominent contribution subsequently has been to develop a more sophisticated understanding of the patterns of diffusion (Lissoni and Metcalfe 1994). Work started with Griliches' (1957) modelling of the diffusion of 
'hybrid corn' which characterised the pattern of diffusion as being represented by the conventional logistic curve used in the marketing literature. Dixon (1980) re-examined Griliches (1957) and found that the asymmetric Gompertz curve was a better representation of the diffusion process in the context of 'hybrid corn'. Lekvall and Wahlbin (1973) use another curve, the modified exponential, to show how different types of communication channels impact the pattern of diffusion. Hence, when the diffusion process is dominated by external communication channels, as distinct to internal communication, the diffusion curve is likely to be better represented by the modified exponential than the logisitic.

Other ' $S$ ' shaped curves used to model the diffusion process that have come to prominence in recent times are the cumulative normal and the cumulative lognormal as expressed in the Davies (1979) innovation diffusion model. Stoneman (2002) notes that the cumulative normal and the cumulative lognormal curves have the advantage of parameter determined inflection points that are fixed for both the logistic and Gompertz curves. Further, the Davies (1979) model has the useful property that it discerns different diffusion patterns for different types of innovations.

Figure 2: The Cumulative Lognormal and Cumulative Normal Curves

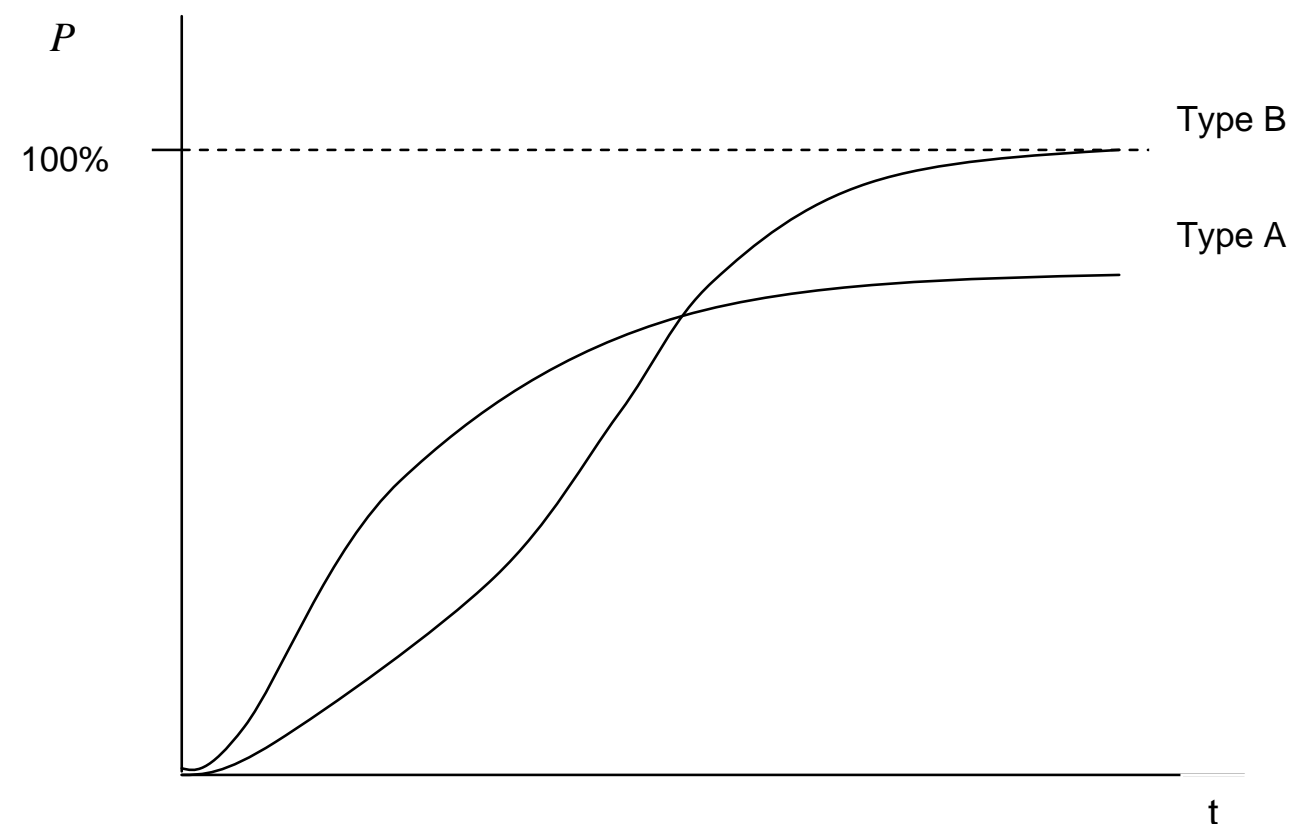




\subsection{Davies (1979) Model and patterns of international diffusion}

The Davies (1979) model uses two curves to distinguish two different functional forms for different types of innovations, with the cumulative lognormal curve representing inexpensive simple innovations (Type A diffusion) and the cumulative normal associated with expensive complex innovations (Type B diffusion). More formally, with $P_{t}$ representing percentage penetration (defined as the proportion of adopters over potential adopters) at time t, then

$$
P(t)=N\left(\log t \mid \mu, \sigma^{2}\right)
$$

is the cumulative lognormal curve representing the Type A diffusion and

$$
P(t)=N\left(t \mid \mu, \sigma^{2}\right)
$$

is the cumulative normal curve depicting Type B diffusion. Stylised versions of both curves are reproduced in Figure 2.

The different mathematical forms (as distinct to the speed or slope) of the two curves are explained by different hurdle pay offs for different types of technologies. Thus, with inexpensive simple innovations, this hurdle pay off is shorter and, consequently, early time periods see greater adoption than in the case of expensive complex innovations, which have longer hurdle pay off periods. Further, complex and expensive Type $B$ innovations will tend to have greater learning benefits over time, which may translate into higher long term profitability and ultimately higher penetration. By way of contrast, simple and inexpensive Type A innovations are more likely to be rapidly replaced by new innovations, though their original diffusion is quicker.

Though the model is one of inter-firm diffusion it has, however, been applied at both the international (Antonelli 1986) and regional levels (Alderman and Davies 1990). Antonelli (1986) tests the Davies (1979) model in the context of the diffusion of 
modems in 16 countries and found that the international pattern of modems diffusion was consistent with the model predictions.

\subsection{Propositions related to induced diffusion}

As observed in the introduction to this paper, the current empirical context allows for the established literature on the patterns of diffusion to be extended to the context of induced diffusion. The a priori expectation is that differences will emerge given that the induced diffusion process is not a 'natural'/unregulated/unfettered market process. To this end, a number of propositions are made in relation to the Davies (1979) model in the international wind energy diffusion context.

\section{Proposition 1: Induced diffusion may result in less smooth or distorted diffusion curves}

The expectation is that the pay off hurdle period will change over time as support for the wind energy industry changes, resulting in less smooth or distorted diffusion curves. This relates to how the political cycle leads to policy reversals and policy changes with respect to how and which externalities are valued and which instruments are used to internalise them (both will vary across countries and within countries over time). For instance, in the US 'Production Tax Credits' and other tax incentives have been an important part of the renewables policy mix since the late 1970s (Norberg-Bohm 2000). However, these tax incentives often come with sunset clauses which have often been allowed to expire before being replaced. These expirations have, in turn, been associated with falls in newly installed capacity in the subsequent years (UCS 2004, Norberg-Bohm 2000). Further, Agnolucci (2006) observes that in the Netherlands a FIT law was introduced following the failure of a tax incentive policy. More generally, research by the EU Commission (2008) shows that the majority of the twenty seven EU member states have changed or adapted their renewable support scheme at least once in the period between 1997 and 2006. 


\section{Proposition 2: Dichotomising Type A and Type B innovations becomes more complex when diffusion is induced}

The expectation is that the model may not be as categorical on dichotomising Type A and Type $B$ technologies as countries that heavily subsidise an industry will create a similar pay off to that of a Type A diffusion when, in fact, the technology displays the characteristics of a Type B diffusion. In other words, large subsidies will have the effect of shortening hurdle pay off period even though on pure technological grounds the technology may be regarded as a Type B technology.

\section{Proposition 3: Induced diffusion will result in greater variability in the speed of diffusion between countries}

In a similar vein, the speed of diffusion will invariably depend on the degree of support for the industry. This is likely to vary between countries since there is no universal agreement ${ }^{2}$ as to what externalities are present, what value should be attached to them and how they should be internalised. It is evident that wind energy has a number of positive and negative externalities that would seem to be absent in an unfettered market cost basis appraisal of the technology. Positive externalities include: environmental benefits from cleaner generation; improved energy security (in a geopolitical sense); and diversification effects (Awerbuch 2000; 2006). Negative externalities might include: energy reliability concerns arising from intermittency; negative environmental impact on wildlife and noise pollution; and political conflict arising from NIMBY opposition to projects. It is clear that different political regimes within countries, never mind international differences, are likely to provide very different valuations to these externalities and different answers as to how to internalise them. ${ }^{3}$ This is likely to result in greater variability in terms of when countries start to adopt the technology and how fast they do so.

In sum, all three propositions are based on the premise that policy interventions can induce diffusion (Jaffe et al. 2002) and that the volatile nature of

\footnotetext{
${ }^{2}$ The EU's Emission Trading Scheme (EU EST) could be seen as a regional attempt to provide harmonised answers to some of these questions.

${ }^{3}$ Expediency means that the discussion of externalities and their valuation are given a crude treatment. This does not belie the existence of a well established literature with its origins in Coase (1960) and which has continued to flourish in various guises but with particular focus on valuation of externalities and instruments with which to internalise them.
} 
policy interventions means that this will cause the patterns of diffusion to alter from their 'natural' patterns.

\subsection{The nature of wind energy technology}

Basic wind turbines can be simple; however, the concern here is with industrial level turbines and wind farms that are connected to electricity grids. EWEA (2009a) contains an explanation of modern wind technologies. Industrial level wind turbines are unambiguously complex innovations. They incorporate a range of technologies including those related to blades, gears, generators and control systems. They need to be integrated to the electricity grid and require detailed pre-installation assessment of site wind resource and geological conditions, as well as the related selection of optimal location/positioning. Wind projects are often subjected to lengthy consultation processes and environmental impact assessments. Industrial scale wind farms are multi-million dollar projects. Therefore, industrial level wind turbines are both complex and expensive innovations; this leads to a fourth proposition:

Proposition 4: Wind energy is a complex and expensive technology that ceteris paribus would display a Type $B$ diffusion curve

The ceteris paribus caveat here is related to Proposition 2. The a priori expectation was that the model would still work as per Proposition 4 but would not be as categorical (Proposition 2).

\section{Design: Estimation and Data}

This section describes the method by which the Davies (1979) model is applied (3.1.), the two datasets used (3.2.) and how diffusion and market saturation are calculated in the context of wind energy (3.3.). 


\subsection{Study design and model estimation}

The econometric analyses that follow take a similar approach to Antonelli (1986). Hence,

$$
P(t)=N\left(\log t \mid \mu, \sigma^{2}\right)
$$

the cumulative lognormal curve (Type A diffusion) is estimated by

$$
\log Y=a+b_{1} \log t
$$

which is the loglogistic. While,

$$
P(t)=N\left(t \mid \mu, \sigma^{2}\right)
$$

the cumulative normal curve (Type B diffusion) is estimated by

$$
\log Y=a+b_{1} t
$$

which is the logistic. Where

$$
Y_{i t}=\frac{P_{i t}}{K_{i t}-P_{i t}}
$$

and $K_{i t}$ is the saturation or ceiling of wind installed capacity diffusion in country i in year $\mathrm{t}$, while $P_{i t}$ was defined below as MW installed wind capacity over total MW installed capacity from all forms of generation country $i$ in year $t$.

\subsection{Data and data problems}

Two wind energy diffusion timeseries are employed. The first is from the IEA's (International Energy Agency) 'Renewables Database' and the second is from BTM 
Consult APS. The focus of the analysis is on OECD countries. A number of OECD countries were excluded from the analysis due to insufficient observations or because they did not have any installed wind capacity (Iceland, the Slovak Republic and Hungary). For the remaining twenty seven OECD countries wind diffusion timeseries existed from both the IEA and BTM datasets except for the Czech Republic where only IEA data is available.

A comparison of the wind installed capacities from both the IEA and BTM timeseries through to 2005 raised a number of data issues, these are summarised in Table 1. These data issues relate both to when the first year of wind energy was installed $(\mathrm{t}=1)$ and the difference between installed capacities in 2005 (referred to as the '2005 differential' and is calculated as the percentage difference between the IEA wind installed capacity in 2005 and the equivalent BTM number in 2005).

With respect to the '2005 differential' it can be stated that, in general, the BTM and IEA data coincide. In most cases the difference is less than 5 per cent and in only six cases is it more than 10 per cent (Greece, Korea, Luxemburg, Poland, Sweden and the UK). By way of reference to the British Wind Energy Association it was possible to confirm that the BTM data was more accurate in the case of the UK. 
Table 1: Data and Data Issues

\begin{tabular}{|c|c|c|c|c|c|c|c|}
\hline Country & $\begin{array}{l}\text { IEA } \\
\mathrm{t}=1\end{array}$ & $\begin{array}{c}\mathrm{BTM} \\
\mathrm{t}=1\end{array}$ & $\begin{array}{l}t=1 \\
\text { Diff }\end{array}$ & $\begin{array}{l}\text { BTM } \\
\text { Trunc. }\end{array}$ & $\begin{array}{l}\text { P } 2005 \\
\text { Diff. }\end{array}$ & Best & Comment \\
\hline \multicolumn{8}{|c|}{ 1. Datasets coincide with respect to $t=1$ (i.e. $t=1$ within one year) and differential of $<10 \%$} \\
\hline Austria & 1995 & 1994 & 1 & no & $0.9 \%$ & BTM & \multirow[t]{7}{*}{$\mathrm{t}=1$ difference explained by rounding } \\
\hline Finland & 1991 & 1991 & 0 & no & $-3.5 \%$ & NC & \\
\hline France & 1991 & 1990 & 1 & no & $-6.6 \%$ & BTM & \\
\hline Ireland & 1992 & 1992 & 0 & no & $-0.7 \%$ & $\mathrm{NC}$ & \\
\hline Italy & 1989 & 1990 & -1 & NM & $-4.6 \%$ & IEA & \\
\hline Portugal & 1989 & 1990 & -1 & no & $-2.1 \%$ & IEA & \\
\hline Turkey & 1998 & 1997 & 1 & no & $4.7 \%$ & BTM & \\
\hline \multicolumn{8}{|c|}{ 2. BTM data more accurate (In most cases difference between datasets explained by IEA rounding) } \\
\hline Australia & 1994 & 1990 & 4 & NM & $3.2 \%$ & BTM & \multirow{10}{*}{$\begin{array}{l}\mathrm{t}=1 \text { diff. mostly explained by rounding } \\
\mathrm{t}=1 \text { difference explained by rounding } \\
\mathrm{t}=1 \text { diff. partly explained by rounding. } \\
\mathrm{t}=1 \text { difference mostly explained by } \\
\text { rounding. IEA Output data starts } 1992 \\
\mathrm{t}=1 \text { difference explained by rounding } \\
\text { IEA Output data and BTM point to } 1993 \text {; } \\
\mathrm{t}=1 \text { diff. mostly explained by rounding } \\
\mathrm{t}=1 \text { diff. mostly explained by rounding } \\
\mathrm{t}=1 \text { difference explained by rounding } \\
\text { Large differential: BWEA coincides with } \\
\text { BTM } \\
\text { BTM data coincides with EWEA (2003) } \\
\text { with respect to } \mathrm{t}=1\end{array}$} \\
\hline Belgium & 1987 & 1980 & 7 & no & $-5.6 \%$ & BTM & \\
\hline Japan & 1993 & 1990 & 3 & no & $5.9 \%$ & BTM & \\
\hline Korea & 1999 & 1991 & 8 & no & $-10.4 \%$ & BTM & \\
\hline Mexico & 1994 & 1991 & 3 & no & $4.3 \%$ & BTM & \\
\hline New Zealand & 1997 & 1993 & 4 & no & $0.4 \%$ & BTM & \\
\hline Norway & 1995 & 1986 & 9 & no & $-1.7 \%$ & BTM & \\
\hline Switzerland & 1996 & 1994 & 2 & no & $7.0 \%$ & BTM & \\
\hline UK & 1989 & 1990 & -1 & NM & $17.1 \%$ & BTM & \\
\hline United States & 1989 & 1981 & 8 & no & $5.5 \%$ & BTM & \\
\hline \multicolumn{8}{|c|}{ 3. IEA Data more accurate (i.e. BTM data truncated) or only option } \\
\hline Czech Rep. & 1998 & $\mathrm{n} / \mathrm{a}$ & $\mathrm{n} / \mathrm{a}$ & $\mathrm{n} / \mathrm{a}$ & $\mathrm{n} / \mathrm{a}$ & $\mathrm{n} / \mathrm{a}$ & \multirow{3}{*}{$\begin{array}{l}\text { BTM truncated and large differential } \\
\text { BTM truncated and large differential }\end{array}$} \\
\hline Greece & 1988 & 1990 & -2 & yes & $-30.4 \%$ & IEA & \\
\hline Poland & 1998 & 2000 & -2 & yes & $85.7 \%$ & IEA & \\
\hline \multicolumn{8}{|c|}{ 4. Not clear which dataset is more accurate } \\
\hline Luxembourg & 1996 & 1996 & 0 & no & $191.7 \%$ & NC & large differential \\
\hline \multicolumn{8}{|c|}{ 5. Both datasets are of concern (i.e. There are specific reasons to doubt both) } \\
\hline Canada & 1990 & 1992 & -2 & no & $0.1 \%$ & Neither & $\begin{array}{l}\text { IEA Output } 1985 \text { before capacity: Both } \\
\text { datasets of concern }\end{array}$ \\
\hline Denmark & 1981 & 1981 & 0 & yes & $1.4 \%$ & Neither & $\begin{array}{l}\text { BTM truncated; which implies start pre- } \\
1981\end{array}$ \\
\hline Germany & 1984 & 1987 & -3 & no & $-0.1 \%$ & Neither & $\begin{array}{l}\text { Third party est.1982; IEA output 1986; } \\
\text { gap in IEA installed cap. (1986 and 1987) }\end{array}$ \\
\hline Netherlands & 1985 & 1990 & -5 & yes & $0.2 \%$ & Neither & Third party est1980; BTM truncated \\
\hline Spain & 1990 & 1990 & 0 & yes & $-1.1 \%$ & Neither & $\begin{array}{l}\text { BTM truncated; implies start pre- } 1990 \text { and } \\
\text { thus brings into question IEA data }\end{array}$ \\
\hline Sweden & 1984 & 1990 & -6 & yes & $-11.0 \%$ & Neither & $\begin{array}{l}\text { BTM truncated, third party estimate of } \\
\text { 1982, IEA output data pointing to } 1983\end{array}$ \\
\hline
\end{tabular}

Key: NM = truncation not material; NC = Not clear which dataset is best

With respect to $t=1$ it is apparent that, in general, BTM data is of greater accuracy than IEA data due to the rounding of IEA data to the nearest $1 \mathrm{MW}$. In this 
sense BTM data is preferable in the vast majority of cases since no matter how small the level of installed capacity, the capacity is measured. However, in a number of cases it was clear that the BTM data was truncated in the sense that BTM coverage of installed capacity came some time after the first installation of wind in the country (this is discernable from the data because the BTM $t=1$ cumulative installed capacity is higher than that added in $\mathrm{t}=1$ ). In some cases this was so small it was deemed not to be material (e.g. in the case of Australia there is a pre $t=1$ legacy installed capacity of $0.6 \mathrm{MW}$ ) while in other cases it was clearly pointing to installed capacity having predated BTM $\mathrm{t}=1$ by quite some time (e.g. the Netherlands where new installed capacity in 1990/t=1 was $15 \mathrm{MW}$ making a total of $40 \mathrm{MW}$, thus $25 \mathrm{MW}$ was pre 1990).

In order to comprehend the implications of the above data issues Table 1 divides countries into five categories. Category 1 reports the countries where there is confidence in both datasets since they coincide to a very high degree $(t=1$ are within one year and differences are largely explained by IEA rounding plus 2005 differentials are less than 10 per cent). Category 2 reports countries where BTM data is preferable due largely to rounding of IEA data or verification of BTM data through a third source (The case of the UK was mentioned above, while $t=1$ for the US was verified through EWEA 2003).

For the countries falling into Categories 3,4 and 5 there are more concerns about data quality. Category 3 covers cases where IEA data is the only option (Czech Republic) or where it is preferable since BTM data is clearly truncated (Greece and Poland $)^{4}$. Category 4 deals with Luxembourg where there is a large unresolved differential yet $\mathrm{t}=1$ is the same for both datasets. Category 5 deals with countries where both datasets are known to be inaccurate or conflict with other data or evidence, including the IEA wind energy output data. This means that the econometric analysis was not undertaken for these countries. Unfortunately many of the countries in Part 5 are some of the biggest and earliest diffusers (Germany, Spain and Denmark). The data problems in these cases clearly reflect that there were few bodies accurately measuring wind penetration in the early years of the current vintage of the technology.

\footnotetext{
${ }^{4}$ There are also large differentials in both these cases
} 


\subsection{Calculating wind penetration and estimating saturation}

Using the two datasets wind penetration $\left(P_{i t}\right)$ is defined as

$$
P_{i t}=\frac{\text { MW installed wind capacity in country } \mathrm{i} \text { in year } \mathrm{t}}{\text { total MW installed capacity from all forms of generation country } \mathrm{i} \text { in year } \mathrm{t}}
$$

The denominator used in both sets of modelling was obtained from the IEA with the exception of Korea where the data was truncated (no total installed capacity pre 1994 presumably because Korea only joined the OECD in 1996). As a result the data for total installed capacity in Korea came from the US EIA database.

This definition of diffusion is consistent with the economics literature where diffusion is always defined as a relative concept, namely the number of adopters at time t over the potential market at time $t$ (See for instance Davies 1979, Stoneman 2002). There can, however, be challenges in defining the potential market.

The use in the study of total MW installed capacity from all sources as the potential market was chosen for several reasons; (1) it is in line with previous work, for instance Antonelli (1986) defined the diffusion of modems relative to telexes installed; (2) it is the most practical definition since the data is readily available and; (3) it can be related to policy targets which are often defined in the same way. An alternative definition might have used total wind resource as the denominator. Putting aside the difficulty of measuring resource over time ${ }^{5}$, this would have proven to be a valid alternative approach and arguably desirable if the countries examined were close to reaching resource saturation. This is not the case for the vast majority of countries in the analysis. ${ }^{6}$ A more pressing constraint currently with respect to wind

\footnotetext{
${ }^{5}$ The feasible resource will increase over time as wind technologies improve, not least in the context of larger wind turbines and as offshore wind technologies develop (EWEA 2009a).

${ }^{6}$ Denmark's onshore penetration of wind energy is extremely high raising doubts about how much further it could be expanded but there remains significant offshore potential, meaning that capacity could still be doubled (EWEA 2009b). Denmark was in any case excluded from the econometrics but it highlights that the systems and cost constraint are likely to be more binding than the resource one. Another country where resource constraint could easily become an issue is Luxembourg since it is a relatively small landlocked country but even there EWEA (2009b, p.10) foresees the potential to expand wind energy up to twentyfold by 2020 relative to 2008 levels. More generally EWEA (2009b) would seem to indicate that in most of the EU countries analysed penetration rates of 30 per cent could be achieved, while their target for the EU as a whole in 2030 is for wind to represent 38 per cent of total electricity generating capacity.
} 
energy would seem to be how much wind can be integrated without affecting system stability or resulting in disproportionately higher system costs to ensure system stability. This is a further reason to use total installed capacity from all sources, since these debates are centred around what proportion of wind energy relative to total current capacity are likely to cause system problems. Alternative views of this 'system' constraint can easily be incorporated into the model by providing different values of $K_{i t}$.

In Section 3.1 it was observed that $K_{i t}$ is defined as the ceiling for wind energy in country i at time t. Harrison and Milborrow (2001) note the consensus amongst utility experts is that "most electricity systems can operate with wind energy penetrations levels approaching 30 per cent, subject to some changes to operating procedures, for very modest extra costs". By way of contrast Sørensen and Meibom (1999) conclude, based on theoretical modelling, that, if the power pool is large enough, then 100 per cent of energy derived from wind could be possible. Interestingly, the Danish experience, where saturation would appear to have been reached at around 25 per cent (see next section) would seem to support the belief that saturation is currently around 30 per cent. Accordingly the econometric modelling will be based on $\mathrm{K}=30$.

It should be noted, however, that the contrasting estimates of $K_{i t}$ by Harrison and Milborrow (2001) and Sørensen and Meibom (1999) can be reconciled. The former was referring to the current level of saturation while the latter explored the context in which saturation might be higher. As observed by Griliches (1980) in his response to Dixon's (1980) re-examination of his earlier work (Griliches 1957), the level of saturation is not likely to be constant over time. In the case of wind energy, the ceiling is likely to change because of grid integration and technological advances.

Energy market liberalisation and integration in Europe has resulted in a growing number of international interconnectors, implying a higher $K$, since a larger pool implies greater ability for the power pool to be stable at higher levels of wind penetration (Sørensen and Meibom 1999). Furthermore, should important advances in electricity storage materialised in the future, then feasible wind penetration could, 
theoretically at least, be $K=100$ given that global wind resources would seem to be larger than current demand. ${ }^{7}$ Though the latter does not seem imminent, it highlights that the use of $\mathrm{K}=30$ in this paper merely represents the best estimate of current wind energy ceiling. ${ }^{8}$

\section{Empirical analyses}

This section addresses the empirical findings. The Section 4.1. provides a descriptive analysis of wind diffusion. Section 4.2. reports the results of the econometric analysis and discusses the reliability of the results. Section 4.3. addresses the implications of the results with respect to the predicted 'functional form' and the four propositions developed. Finally, the results of the modelling enable a comparative analysis of the speed of diffusion and 'rate of acceptance' in OECD countries (Section 4.4.).

\subsection{Leaders, laggards and levels of diffusion}

On computing $P_{i t}$ (See Figure 3), it becomes evident that diffusion of wind energy is most advanced in three countries; Denmark, Germany and Spain.

Denmark, in turn, has a large lead over Spain and Germany but the diffusion process would appear to have reached a ceiling in Denmark. This is likely to be due to 'system' or cost constraints as opposed to a resource constraint. ${ }^{9}$ Further, Figure 3 highlights that six countries had achieved diffusion levels of over 5 per cent by 2005 . Figure 4 shows the countries on which the econometric analysis is carried out on and serves well to illustrate the diffusion of wind energy in these countries since it excludes the three big diffusers. Further, Table 1 and Figure 3 also highlight that the large majority of OECD countries started installing and deriving electricity from wind

\footnotetext{
${ }^{7}$ This is certainly true once offshore wind is added into the equation. Estimates of total global wind resource vary greatly though most put the resource above current demand. See for instance EWEA (2003, p.43-44) and Neuhoff (2005).

${ }^{8}$ An alternative approach might have calculated a different value of $\mathrm{K}$ for each country that took account of both system and resource constraints, however, an earlier version of this paper modelled a range of values for $\mathrm{K}$ and found that there was very low or nil fit differences between the different values of $\mathrm{K}$.

${ }^{9}$ See Footnote 6
} 
energy throughout the 1990s. ${ }^{10}$ The 'lead market' (Beise 2004) is clearly Denmark even though a number of other countries experimented with wind energy in the early 1980 s as a result of the oil shocks of the 1970s. Figure 5 shows that there are large regional differences, with most wind diffusion having occurred in Europe, though, as noted in Section 1.2., this situation has started to change since 2005.

\footnotetext{
${ }^{10}$ In a number of cases it can be seen that the proportion of wind energy decreases overtime. This reflects the fact that the denominator, Total Installed Capacity $\left(P_{i t}\right)$ is just as likely to change (increase) over time as the numerator.
} 
Figure 3: Wind installed capacity as percentage of installed capacity $\left(P_{i t}\right)$ from IEA dataset (1981 to 2005)

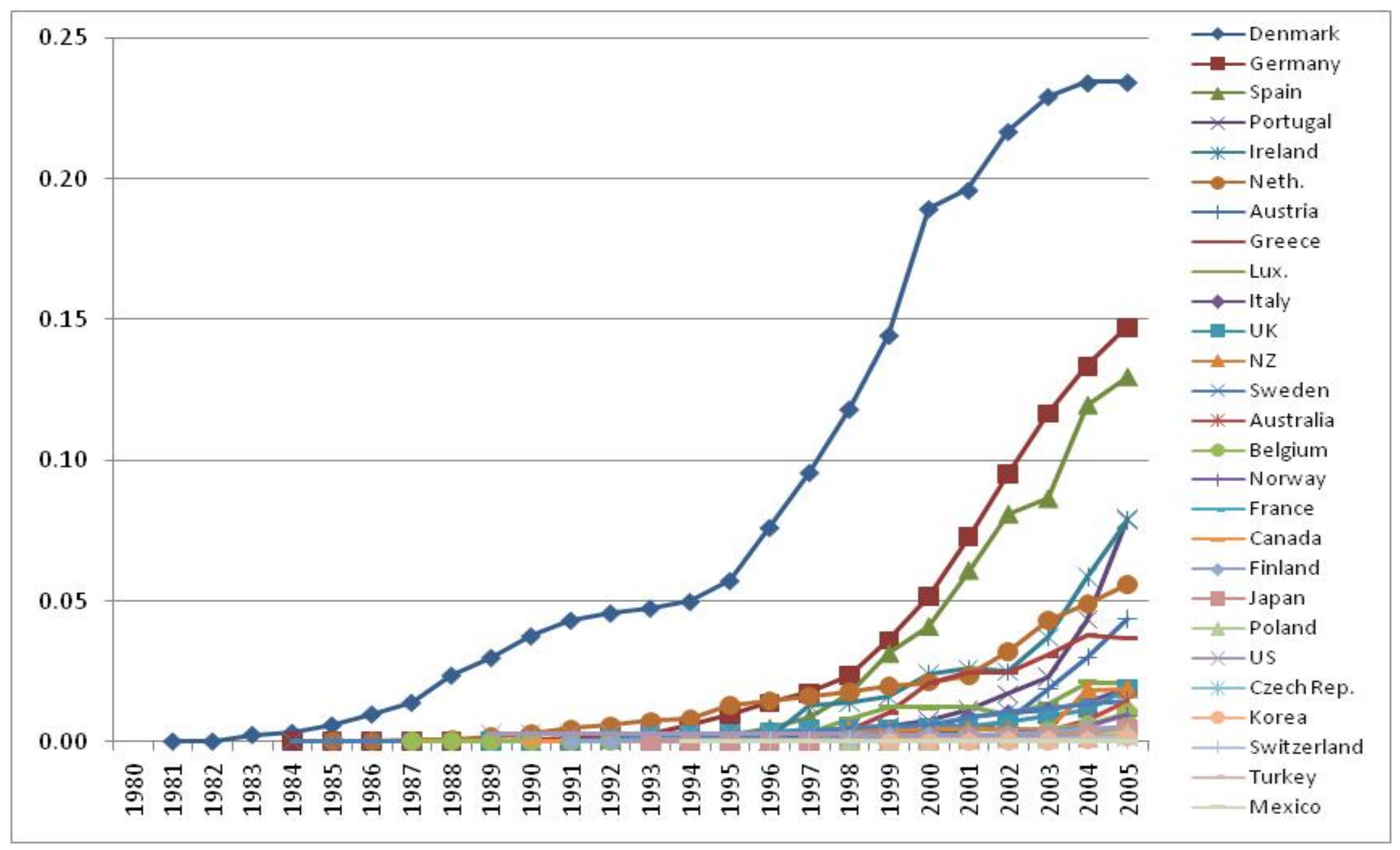


Figure 4: $P_{i t}$ for selected countries from IEA dataset (1987 to 2005)

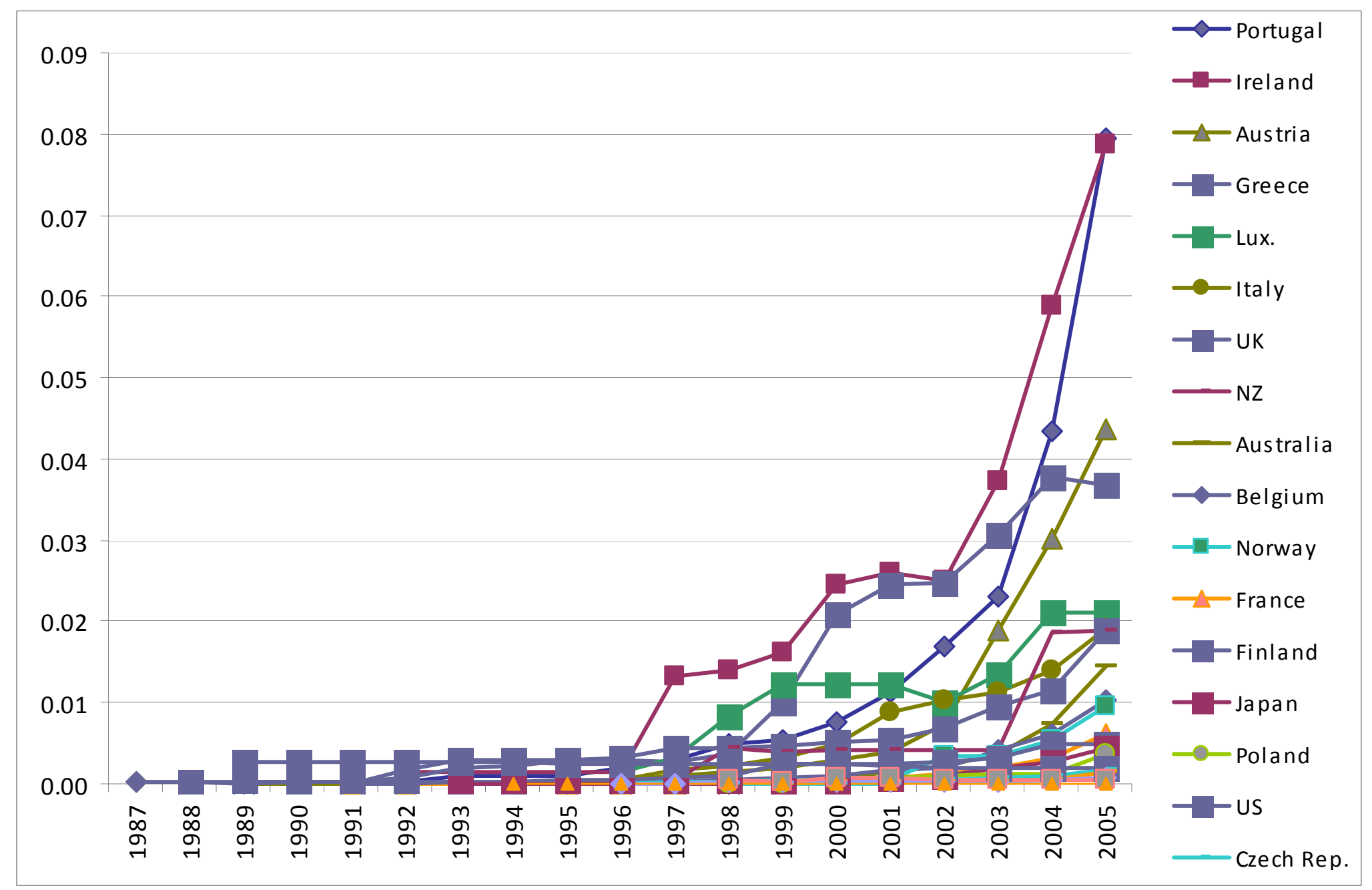


Figure 5: Percentage Installed Capacity for the OECD and OECD regions from the IEA dataset

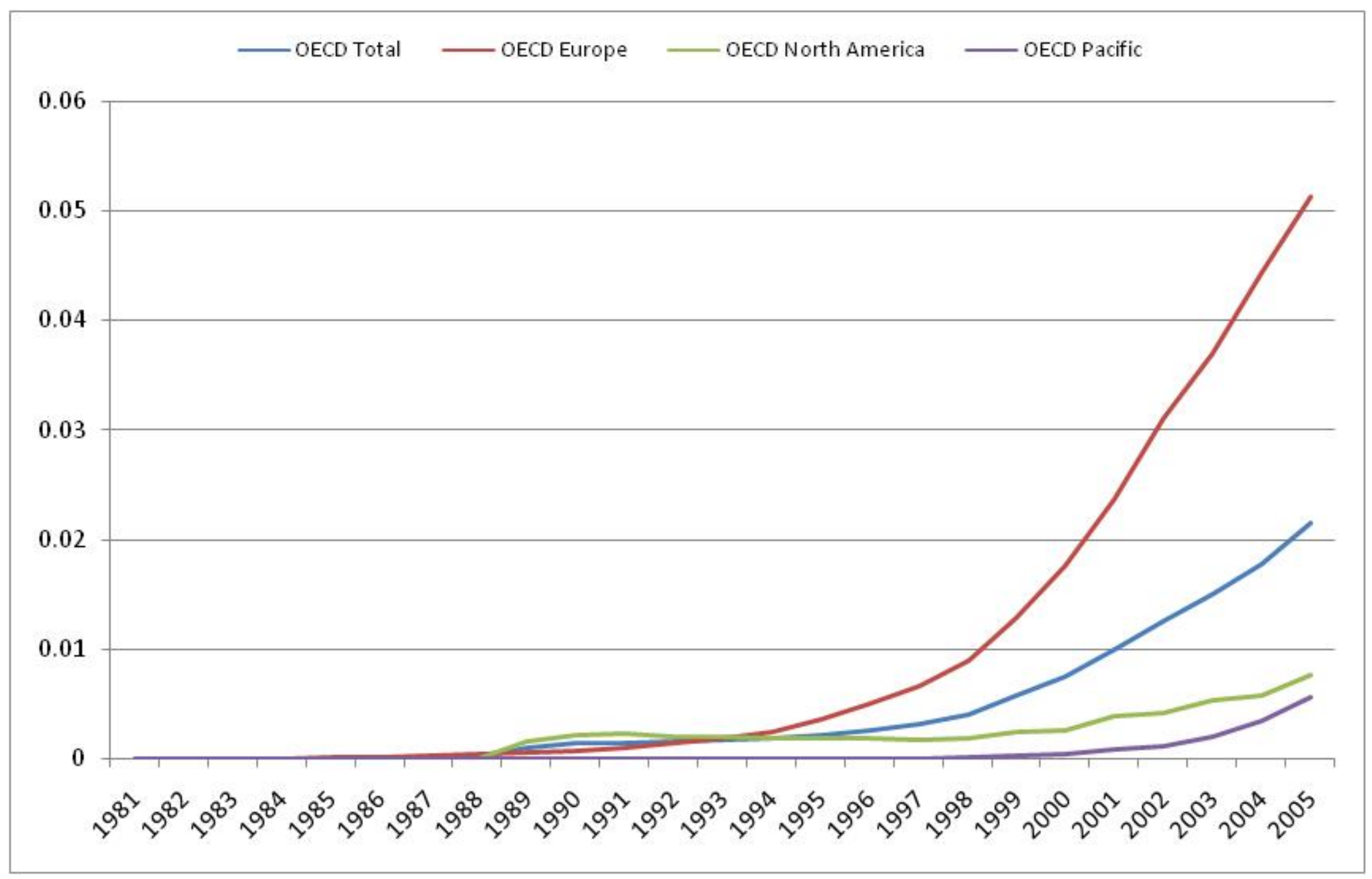


The overriding conclusion of this descriptive analysis is that; (1) as shown by the Danish case, high levels of diffusion can be achieved as a proportion of total installed capacity ${ }^{11}$; (2) the levels of diffusion in most countries are low, indicating that wind energy appears to be in the early stage of diffusion in most countries.

\subsection{Econometric modelling: Results and reliability}

Table 2 and Table 3 list the results of fitting equations 4 and 6 for the IEA and BTM datasets respectively, while Table 4 provides a comparison of the two sets of results. From Tables 2 and 3 it can be seen that on the whole the results from the modelling were good with high $R^{2}$ and satisfactory $\mathrm{t}$ statistics reported in all but a few cases. The tables also report the Durbin Watson (DW) statistics which provides a standard test for the appropriateness of the mathematical form (Alderman and Davies 1990, p.527). As might be expected, in the majority of cases a dominant $R^{2}$ for either of the two curves was associated with a correspondingly better DW statistic than the alternative curve (the exceptions were Greece and New Zealand in the IEA dataset and the US in the BTM dataset). This leads to a high degree of confidence about the results within each of the two datasets, which then naturally leads to a need to explore the reliability across the two datasets.

\footnotetext{
${ }^{11}$ Clearly the cost of achieving this level of diffusion needs to be considered.
} 
Table 2: Curve fitting with the IEA dataset $(K=30 \%)$

\begin{tabular}{|c|c|c|c|c|c|c|c|c|c|c|c|c|}
\hline \multirow[b]{2}{*}{ Country } & \multirow[b]{2}{*}{ \# years } & \multicolumn{5}{|c|}{ IEA Cumulative normal (Type B) $K=30$} & \multicolumn{5}{|c|}{ IEA Cumulative lognormal (Type A), $K=30$} & \multirow{2}{*}{$\begin{array}{c}\text { R2: Type } \\
\text { A or B? }\end{array}$} \\
\hline & & a & b & $P>|t|$ & R2 & DW & a & b & $P>|t|$ & R2 & DW & \\
\hline Australia & 12 & -10.286 & 0.587 & 0.000 & 0.938 & $0.580^{*}$ & -10.569 & 2.462 & 0.000 & 0.725 & $0.441^{*}$ & B \\
\hline Austria & 11 & -7.978 & 0.572 & 0.000 & 0.936 & 1.392 & -8.596 & 2.545 & 0.000 & 0.935 & $0.544^{\star}$ & B \\
\hline Czech Republic & 8 & -9.564 & 0.527 & 0.001 & 0.871 & 1.374 & -9.335 & 1.616 & 0.012 & 0.675 & $0.940\left(^{*}\right)$ & B \\
\hline Finland & 15 & -8.157 & 0.297 & 0.000 & 0.930 & $1.305\left(^{*}\right)$ & -8.945 & 1.702 & 0.000 & 0.932 & 1.695 & A \\
\hline France & 15 & -11.248 & 0.469 & 0.000 & 0.977 & $1.311\left(^{*}\right)$ & -12.013 & 2.430 & 0.000 & 0.801 & $0.428^{\star}$ & B \\
\hline Italy & 17 & -9.307 & 0.413 & 0.000 & 0.979 & $1.078^{*}$ & -10.439 & 2.459 & 0.000 & 0.863 & $0.510^{*}$ & B \\
\hline Japan & 13 & -12.985 & 0.697 & 0.000 & 0.926 & $0.642^{*}$ & -13.588 & 3.161 & 0.000 & 0.735 & $0.455^{\star}$ & B \\
\hline Korea & 7 & -8.794 & 0.451 & 0.000 & 0.928 & 1.686 & -8.646 & 1.359 & 0.003 & 0.848 & $1.139\left(^{*}\right)$ & B \\
\hline Luxembourg & 10 & -4.765 & 0.240 & 0.001 & 0.747 & $0.768^{*}$ & -5.090 & 1.091 & 0.000 & 0.903 & $1.162\left(^{*}\right)$ & A \\
\hline Mexico & 12 & -8.521 & 0.008 & 0.680 & 0.044 & $0.840^{*}$ & -8.575 & 0.064 & 0.278 & 0.116 & $0.923^{*}$ & A \\
\hline New Zealand & 9 & -5.748 & 0.321 & 0.007 & 0.671 & 1.856 & -5.937 & 1.261 & 0.004 & 0.714 & 1.620 & A \\
\hline United Kingdom & 17 & -7.693 & 0.312 & 0.000 & 0.809 & $0.379^{\star}$ & -9.156 & 2.166 & 0.000 & 0.970 & $0.908^{\star}$ & A \\
\hline United States & 17 & -4.604 & -0.024 & 0.000 & 0.826 & $0.289^{\star}$ & -4.569 & -0.127 & 0.000 & 0.576 & $0.214^{\star}$ & B \\
\hline
\end{tabular}

* Indicating evidence of positive autocorrelation at the 5\% level; $\left(^{*}\right)$ Denotes an inconclusive DW value at the $5 \%$ level 
Table 3: Curve fitting with the BTM dataset $(K=30 \%)$

\begin{tabular}{|c|c|c|c|c|c|c|c|c|c|c|c|c|}
\hline \multirow[b]{2}{*}{ Country } & \multirow[b]{2}{*}{ \# years } & \multicolumn{5}{|c|}{ BTM Cumulative normal (Type B) $K=30$} & \multicolumn{5}{|c|}{ BTM Cumulative lognormal (Type A), K=30 } & \multirow{2}{*}{$\begin{array}{c}\text { R2: Type } \\
\text { A or B? }\end{array}$} \\
\hline & & $\mathbf{a}$ & b & $P>|t|$ & R2 & DW & $\mathbf{a}$ & b & $P>|t|$ & R2 & DW & \\
\hline Austria & 12 & -9.632 & 0.705 & 0.000 & 0.883 & $0.803^{\star}$ & -10.910 & 3.520 & 0.000 & 0.967 & 1.596 & A \\
\hline Finland & 15 & -8.226 & 0.305 & 0.000 & 0.938 & $1.017^{*}$ & -9.046 & 1.754 & 0.000 & 0.946 & 1.469 & A \\
\hline France & 16 & -12.348 & 0.540 & 0.000 & 0.980 & 1.920 & -13.789 & 3.147 & 0.000 & 0.913 & $0.525^{\star}$ & B \\
\hline Greece & 16 & -6.403 & 0.324 & 0.000 & 0.929 & $0.975^{\star}$ & -7.198 & 1.851 & 0.000 & 0.833 & $0.557^{*}$ & B \\
\hline Ireland & 14 & -5.913 & 0.355 & 0.000 & 0.937 & $1.136\left(^{*}\right)$ & -6.473 & 1.789 & 0.000 & 0.817 & $0.752^{*}$ & B \\
\hline Korea & 15 & -11.864 & 0.416 & 0.000 & 0.893 & $1.116\left(^{*}\right)$ & -12.362 & 2.059 & 0.000 & 0.668 & $0.556^{*}$ & B \\
\hline Luxembourg & 10 & -5.243 & 0.183 & 0.005 & 0.644 & $0.957\left(^{*}\right)$ & -5.556 & 0.872 & 0.000 & 0.860 & $1.176\left(^{*}\right)$ & A \\
\hline Mexico & 15 & -10.266 & 0.164 & 0.017 & 0.366 & $0.765^{\star}$ & -11.276 & 1.249 & 0.000 & 0.648 & $1.207\left(^{*}\right)$ & A \\
\hline New Zealand & 13 & -9.529 & 0.575 & 0.000 & 0.872 & $1.086\left(^{*}\right)$ & -10.613 & 2.947 & 0.000 & 0.884 & 1.644 & A \\
\hline Norway & 20 & -11.301 & 0.371 & 0.000 & 0.927 & $0.758^{\star}$ & -12.933 & 2.610 & 0.000 & 0.867 & $0.508^{\star}$ & B \\
\hline Poland & 6 & -7.562 & 0.518 & 0.060 & 0.629 & $1.308\left(^{*}\right)$ & -7.605 & 1.691 & 0.000 & 0.843 & $1.278\left(^{*}\right)$ & A \\
\hline United States & 25 & -7.001 & 0.141 & 0.000 & 0.617 & $0.338^{*}$ & -8.581 & 1.473 & 0.000 & 0.861 & $0.330^{*}$ & A \\
\hline
\end{tabular}

* Indicating evidence of positive autocorrelation at the 5\% level; $\left(^{*}\right)$ Denotes an inconclusive DW value at the $5 \%$ level 
Table 4: Summary of Curve Fitting Results

\begin{tabular}{|c|c|c|c|c|c|c|c|}
\hline Country & IEA $t=1$ & BTM t=1 & $\begin{array}{c}\text { BTM }^{a} \\
(P=2005)\end{array}$ & $\begin{array}{l}2005 \\
\text { Diff. }\end{array}$ & IEA & BTM & $\begin{array}{l}\text { Funct. } \\
\text { Form }\end{array}$ \\
\hline \multicolumn{8}{|c|}{ 1. Datasets within one year with respect to $t=1$ and differential of $<10 \%$} \\
\hline Austria & 1995 & 1994 & $4.334 \%$ & $0.9 \%$ & B & B & Same \\
\hline Finland & 1991 & 1991 & $0.516 \%$ & $-3.5 \%$ & A & A & Same \\
\hline France & 1991 & 1990 & $0.669 \%$ & $-6.6 \%$ & B & $\mathrm{B}$ & Same \\
\hline Ireland & 1992 & 1992 & $7.936 \%$ & $-0.7 \%$ & B & $\mathrm{B}$ & Same \\
\hline Italy & 1989 & 1990 & $2.004 \%$ & $-4.6 \%$ & B & B & Same \\
\hline Portugal & 1989 & 1990 & $8.117 \%$ & $-2.1 \%$ & B & B & Same \\
\hline Turkey & 1998 & 1997 & $0.052 \%$ & $4.7 \%$ & A & A & Same \\
\hline \multicolumn{8}{|c|}{ 2. BTM data more accurate } \\
\hline Australia & 1994 & 1990 & $1.409 \%$ & $3.2 \%$ & B & A & Diff \\
\hline Belgium & 1987 & 1980 & $1.099 \%$ & $-5.6 \%$ & B & B & Same \\
\hline Japan & 1993 & 1990 & $0.418 \%$ & $5.9 \%$ & B & $\mathrm{B}$ & Same \\
\hline Korea & 1999 & 1991 & $0.142 \%$ & $-10.4 \%$ & B & B & Same \\
\hline Mexico & 1994 & 1991 & $0.006 \%$ & $4.3 \%$ & $A$ & $A$ & Same \\
\hline New Zealand & 1997 & 1993 & $1.884 \%$ & $0.4 \%$ & $A$ & A & Same \\
\hline Norway & 1995 & 1986 & $0.966 \%$ & $-1.7 \%$ & B & B & Same \\
\hline Switzerland & 1996 & 1994 & $0.059 \%$ & $7.0 \%$ & B & A & Diff \\
\hline United Kingdom & 1989 & 1990 & $1.622 \%$ & $17.1 \%$ & A & $A$ & Same \\
\hline United States & 1989 & 1981 & $0.859 \%$ & $5.5 \%$ & B & A & Diff \\
\hline \multicolumn{8}{|c|}{ 3. IEA Data more accurate or only option } \\
\hline Czech Republic & 1998 & $\mathrm{n} / \mathrm{a}$ & $0.167 \%$ & $\mathrm{n} / \mathrm{a}$ & B & $\mathrm{n} / \mathrm{a}$ & $\mathrm{n} / \mathrm{a}$ \\
\hline Greece & 1988 & 1990 & $5.298 \%$ & $-30.4 \%$ & B & $B$ & Same \\
\hline Poland & 1998 & 2000 & $0.202 \%$ & $85.7 \%$ & B & A & Diff \\
\hline \multicolumn{8}{|c|}{ 4. Not clear which dataset is more accurate } \\
\hline Luxembourg & 1996 & 1996 & $0.722 \%$ & $191.7 \%$ & A & A & Same \\
\hline \multicolumn{8}{|l|}{ Summary } \\
\hline & & & & Data & IEA & BTM & Best \\
\hline \multicolumn{5}{|c|}{ Countries } & 21 & 20 & \multirow{5}{*}{$\begin{array}{r}21 \\
9 \\
12 \\
13\end{array}$} \\
\hline \multicolumn{5}{|c|}{ Type A curves dominant } & 6 & 10 & \\
\hline \multicolumn{5}{|c|}{ Type $B$ curves dominant } & 15 & 10 & \\
\hline \multicolumn{5}{|c|}{ DW unsatisfactory or inconclusive for dominant curve } & 10 & 14 & \\
\hline \multicolumn{5}{|c|}{ DW unsatisfactory or inconclusive for Type B curve } & 10 & 17 & \\
\hline
\end{tabular}

$a=I E A$ data in the case Czech Republic 
In 16 of the of 20 cases where there were both IEA and BTM time series for a country the modelling gave equivalent results, meaning that a dominant Type $B$ curve in the curve fitting using the IEA dataset corresponded with a dominant Type B curve when the BTM data was used. This is reassuring, since, as noted earlier, in each of the two datasets different deficiencies depending on the country in question had been identified. These differences led to the grouping of countries into five categories (see Section 3).

With respect to Category 1 countries, the concurrence of results is not surprising since these countries had time series that were very similar. More surprising is the concurrence in the modelling for the other three categories modelled since larger differences in terms of $\mathrm{t}=1$ and levels of diffusion, or both, were apparent. These results show that this type of curve fitting is not as sensitive to differences in $\mathrm{t}=1$ and levels of diffusion as might have been presumed. In the four cases where differences did emerge, a preferred dataset had been identified a priori. Hence in the case of Australia, Switzerland and the United States the BTM results are preferable, while in the case of Poland the opposite is true (see Table 1).

\subsection{Functional Form and the Four Propositions}

Lending weight to Proposition 4 Type B curves provided better fits in 71 per cent (15 out of 21 ) of cases as measured by $R^{2}$ for the IEA dataset (Table 2). This was not the case for the BTM dataset where in only half of the 20 cases modelled did the Type B curve dominate (Table 3), thus lending weight to Proposition 2, namely that dichotomising between Type A and Type $B$ curves becomes more difficult when diffusion is induced. When the 'best' dataset for each country is considered (see Section 3) in 57 per cent of cases Type B curves dominate, again strongly favouring Proposition 2.

These results are best understood in the context of past applications of Davies (1979) model. Antonelli (1986) expected Type B curves to dominate in his study of the international diffusion of modems, with this actually being the case in 81 per cent of the countries in his sample $(n=16)$. Davies (1979) 
explored the diffusion of twenty two process innovations in the UK. In all of the seven innovations where, a priori, a Type B curve was predicted, a Type $B$ curve dominated when the empirical data was applied to the model. In Alderman and Davies (1990), four innovations were examined in the UK at the regional level. In two of those cases, commercial computers and computerised numerically controlled machine tools (CNC), the ex ante expectation was for Type B curves. In the first of these innovations, commercial computers, the empirical analyses found that in all regions, as predicted, the cumulative normal dominated the cumulative lognormal. In the case of CNC, the curve fitting was done twice. In the first instance, 67 per cent (6/9) of the regions had dominant Type B curves. The second set of curve fitting was undertaken on an extended timeseries with the results showing an improved performance of the model; 89 per cent (8/9) of the regions had a dominant Type $B$ curve.

The improving performance of the model in the case of $\mathrm{CNC}$ highlights the possibility that the results presented in Table 2 and Table 3 are not as conclusive in dichotomising between Type $A$ and Type $B$ curves because wind energy diffusion is too near the origin for the model to be effectively tested, rather than because Proposition 2 holds. Though this remains a possibility it is unlikely since the current modelling is an updated version of earlier modelling which used data through to 2002 and if anything the results have become more conclusive toward Propositions 2, this is especially the case when the 'best' datasets are considered.

Proposition 1, which can be read as implying that, at least in some cases, the patterns of diffusion are not ' $S$ ' shaped is best measured against the DW statistic which tests for the appropriateness of the functional form. In this respect and in general the DW statistics were poor. If one observes the best dataset (be it IEA or BTM) and the best curve within the best dataset (Type A or Type B) in just over half the cases (13/21) the DW statistic is unsatisfactory or inconclusive. If we take Proposition 4 at face value and expect wind diffusion to produce Type B curves then there is a mixed picture 
between the two datasets in terms of appropriateness of functional form. For the BTM datasets, nearly all (17/20) the fittings of the logistic implied an unsatisfactory or inconclusive DW, meaning that a Type $B$ pattern was a very poor reflection of the diffusion process. For the IEA dataset, the DW statistics were better, with about half of the logistic curves providing adequate DW statistics. However, as noted in the discussion of the datasets the results of BTM dataset are likely to be more valid due to the rounding employed by IEA which systematically underestimated $t=1$, this may in turn reflect the better performance of the IEA dataset with respect to the DW statistics.

Overall the DW statistics would seem to support Proposition 1. However caution is needed on two accounts (1) there are some concerns about the use of the DW in this context (Alderman and Davies1990; p.518) and (2) though the DW statistics were poorer in this study than in previous applications of the Davies (1979) model there are prior examples where DW statistics were also of concern. For instance, in Antonelli (1986) Type B curves dominated in terms of $R^{2}$ and DW as expected, however, the DW statistics were in general poor.

Finally with respect to Proposition 3 , it is evident that Denmark is the 'lead market' with respect to the diffusion of wind energy. All but a handful of countries lagged at least seven years behind, which seemed slow compared to Antonelli (1986), where nearly all countries followed the lead market within ten years. This cannot, however, be attributed to diffusion being induced since it may merely reflect differences in the technologies being analysed (Canepa and Stoneman 2004), time periods covered or countries covered by this and the Antonelli (1986) study. A suitable test with which to formally assess Proposition 3 was not apparent and as such this proposition remains untested, thus representing a potentially interesting avenue for further research. Whether a suitable empirical test can be created is not clear, so theoretical research may be the way forward. 


\subsection{Speed of diffusion and 'rate of acceptance'}

The 'rate of acceptance' at the country level can be measured by the values of the slope of the fitted curves i.e. the $\hat{b}$ coefficients of Table 2 and Table $3{ }^{12}$ For each of the four curves estimated, the $\hat{b}$ coefficients have been ordered ( 1 = fastest; 20 = slowest) and reported in Table 5, with a higher $\hat{b}$ coefficient representing a faster 'rate of acceptance' and vice versa. It is evident from Table 5 that, in general, a group of countries with a high 'rate of acceptance' (Austria, New Zealand, France and Japan) and a group with of slow 'rate of acceptance' (Switzerland, Turkey, Finland, UK, Luxembourg, Mexico and the US) can be discerned, irrespective of functional form. Interestingly, however, there are a few cases, notably Belgium, Norway and Poland, where large reversals in ranking based on functional form are apparent.

${ }^{12}$ Dixon (1980) described the slope parameter as the 'rate of acceptance'. In this research, $b_{1}$ of equations 4 and 6 is also described as the 'rate of acceptance' and should be distinguished from public acceptance of wind energy projects in an attitudinal sense (see Section 1.2.) 
Table 5: 'Rate of acceptance' and speed of diffusion

\begin{tabular}{|l|c|c|cc|cc|cc|}
\hline Country & $\begin{array}{c}\text { \# } \\
\text { years }\end{array}$ & $\begin{array}{c}\text { p= } \\
\mathbf{2 0 0 5}\end{array}$ & \multicolumn{2}{|c|}{$\begin{array}{c}\text { Functional } \\
\text { From }\end{array}$} & \multicolumn{2}{c|}{$\begin{array}{c}\text { 'Rate of } \\
\text { acceptance' }\end{array}$} & \multicolumn{2}{c|}{ Speed of Diffusion } \\
Type B & $\begin{array}{c}\text { Type A } \\
\text { Type B }\end{array}$ & $\begin{array}{c}\text { Type A } \\
\text { (BTM) }\end{array}$ \\
\hline Austria & 12 & 4.33 & B & Same & 1 & 1 & 1 & 1 \\
NZ & 13 & 1.88 & A & Same & 2 & 3 & 2 & 3 \\
Portugal & 16 & 8.12 & B & Same & 7 & 7 & 3 & 2 \\
France & 16 & 0.67 & B & Same & 3 & 2 & 4 & 4 \\
Poland & 6 & 0.20 & A & Diff & 4 & 15 & 5 & 15 \\
Australia & 16 & 1.41 & A & Diff & 6 & 8 & 6 & 5 \\
Ireland & 14 & 7.94 & B & Same & 11 & 12 & 7 & 9 \\
Japan & 16 & 0.42 & B & Same & 5 & 4 & 8 & 6 \\
Italy & 16 & 2.00 & B & Same & 8 & 6 & 9 & 7 \\
Korea & 15 & 0.14 & B & Same & 9 & 10 & 10 & 12 \\
Greece & 16 & 5.30 & B & Same & 13 & 11 & 11 & 10 \\
Norway & 20 & 0.97 & B & Same & 10 & 5 & 12 & 8 \\
Switzerland & 12 & 0.06 & A & Diff & 12 & 16 & 13 & 16 \\
Turkey & 9 & 0.05 & A & Same & 14 & 17 & 14 & 17 \\
Finland & 15 & 0.52 & A & Same & 15 & 14 & 15 & 13 \\
UK & 16 & 1.62 & A & Same & 16 & 13 & 16 & 14 \\
Belgium & 26 & 1.10 & B & Same & 17 & 9 & 17 & 11 \\
Luxembourg & 10 & 0.72 & A & Same & 18 & 20 & 18 & 20 \\
Mexico & 15 & 0.01 & A & Same & 19 & 19 & 19 & 19 \\
US & 25 & 0.86 & A & Diff & 20 & 18 & 20 & 18 \\
\hline
\end{tabular}

Though informative, the 'rate of acceptance' is not a particularly good measure of speed of diffusion since it does not reflect absolute levels of diffusion achieved. Poznanski (1983, p.307) defines speed of diffusion as "the number of years elapsed between the first application of the invention and the year in which the share of innovations in the total production reached a particular level". In this respect, Table 5 also outlines the results of calculating the speed of diffusion by solving for $\hat{t}$ based on the fitted results of equations 4 and 6 for $P=30$. Hence, 'speed of diffusion' estimates when countries in the sample will reach levels of diffusion of 30 per cent, for both functional forms, taking into account actual levels of diffusion achieved by 2005. Again the results are ordered with $1=$ fastest and $20=$ slowest.

As with the 'rate of acceptance', irrespective of the functional form a group of fast diffusers (Austria, New Zealand, Portugal and France) and a group of slow diffusers (Switzerland, Turkey, Finland, UK, Belgium, 
Luxembourg, Mexico and the US) are apparent from Table 5. The 'rate of acceptance' and speed of diffusion rankings give broadly equivalent results with the exceptions being Portugal and Ireland. In these cases, the speed of diffusion better reflects the high absolute levels of diffusion achieved in these two countries.

\section{Conclusions}

The main contribution of this study has been to frame a question which is principally of academic interest, namely: Are the patterns of innovation diffusion different when diffusion is induced? The paper develops a number of propositions around Davies (1979) model of innovation diffusion suggesting that the patterns of induced diffusion are likely to be different. These propositions were applied to the context of the international diffusion of wind energy using two datasets covering OECD countries.

Proposition 4 suggested that, ceteris paribus, as a complex and expensive technology, wind energy diffusion should best be characterised by a Type B curve (logistic or cumulative normal). However, the empirical results showed that as expected in Proposition 2, dichotomising between Type A and Type $B$ curves becomes more difficult when diffusion is induced. This result suggests that a Type A diffusion pattern may in some cases provide a better representation of the patterns of induced diffusion despite the technology being unambiguously complex and expensive (Type B; Proposition 4). In addition, there was some evidence to support the notion that the patterns of induced diffusion may not be ' $S$ ' shaped in some cases (Proposition 1) but concerns about the DW test statistics means that the most that can be said at this point is that this possibility can not be rejected.

With respect to Proposition 1, it is important to emphasize that it only suggests that the pattern of induced diffusion may not be ' $S$ ' shaped in some cases. These are likely to be those where there have been a lot of policy changes in terms of the support used to induce diffusion. It is clear from the results of the modelling that whether a Type A or Type B curve provided the 
best fit, an 'S' shape curve still provided a good representation of the diffusion in approximately half the cases (when observing the 'best' dataset and best fit curve). This in turn has an interesting policy implication since many targets have been developed by policymakers that are symmetrical in nature and do not account for learning that is implicit in diffusion curves. For instance, in the UK symmetrical policy targets exist whereby renewables should reach 10 per cent by 2010 and 20 per cent by 2020 (DTI 2003) implying a linear diffusion process. This is inconsistent with historical patterns of diffusion. Policy targets should take account of learning; failure to do so may result in early reversal of policies that may ultimately have succeeded.

In a further policy related point, the results of the empirics were used to calculate the speed of diffusion (as distinct to the 'rate of acceptance') amongst the OECD countries modelled. It was found that a group of fast diffusers (Austria, New Zealand, Portugal and France) and a group of slow diffusers (Switzerland, Turkey, Finland, UK, Belgium, Luxembourg, Mexico and the US) could be identified. These results could, in future research (see next section), be used as the dependent variables in the modelling of the determinants of wind energy diffusion and shed further light in the debate concerning the efficacy and efficiency of competing investment support schemes for renewables (Agnolucci 2007 and Kildegaard 2008).

Overall the results with respect to functional form suggest that the patterns of induced diffusion are considerably different to those observed conventionally. These results in turn imply that policies to induce diffusion do work since the construction of Propositions 1 and Proposition 2 are underpinned by the notion that diffusion can be induced. The results are, therefore, consistent with the consensus in the induced diffusion literature that diffusion can be induced (Jaffe et al. 2002).

\subsection{Limitations and further research}

The limitations of both datasets discussed in Section 3.2. highlights the need for further empirical research on the patters of induced diffusion using 
different datasets and in different contexts. If future research confirms that inducing diffusing does affect functional form then the next question will be to explore how functional form is affected by different instruments. This in turn, will provide insights into the effectiveness of competing instruments which can be reconciled to the understanding established in the induced diffusion literature. The exercise would then merge into exploring both the patterns and determinants of induced diffusion.

This last point highlights related limitations of this paper, namely it has not modelled price in any way. Price would be interesting to explore from a number of perspectives. For instance, it would be interesting to investigate what effect different policies in different countries have had on price of wind energy relative to fossil fuels and how these price differences have affected technology choice and diffusion more generally. Such empirical work could build on dynamic models of energy system change (Anderson and Winne 2007). A further limitation of the paper is that it has not explicitly modelled the learning experienced in the wind energy industry over the last few decades (See Section 1.2.). ${ }^{13}$ The concern in this paper has been a more modest and principally academic one, namely to understand whether the patters of induced diffusion are different to the ones conventionally observed. The contribution of this paper has been to frame this question and to provide some initial empirical evidence in this regard.

\footnotetext{
${ }^{13}$ Although learning and related cost reductions were not explicitly modelled it is worth noting that they are implicit in the functional ' $S$ ' shaped form of diffusion conventionally observed, indeed as noted in Section 2.1. the distinction between Type A and Type B diffusion in the Davies model (1979) relates, in part, to different rates of learning between different types of technologies.
} 


\section{References}

Agnolucci, P., 2007. The effect of financial constraints, technological progress and long-term contracts on tradable green certificates. Energy Policy 35(6), 3347-3359.

Alderman, N., Davies, S., 1990. Modelling regional patterns of innovation diffusion in the UK metalworking industries. Regional Studies 24 (6), 513-528.

Anderson, D., 2007. Electricity generation costs and investment decisions: A review. UKERC Working Papers, February, UK Energy Research Centre, London.

Anderson, D., Winne, S., 2007. Energy system change and external effects in climate change mitigation. Environment and Development Economics 12 (3), 359-378.

Antonelli, C., 1986. The international diffusion of new information technologies. Research Policy 15(3), 139-147.

Awerbuch, S., 2000. Investing in photovoltaics: risk, accounting and the value of technology. Energy Policy 25, 1023-1035.

Awerbuch, S., 2006. Portfolio-based electricity generation planning. Mitigation and Adaptation Strategies for Global Change 11, 693-710.

Beise, M., 2004. Lead markets: country-specific drivers of the global diffusion of innovations. Research Policy 33, 997-1018.

Beise, M., Rennings, K., 2005. Lead markets and regulation: a framework for analyzing the international diffusion of environmental innovations. Ecological Economics 52, 5-17.

Canepa, A., Stoneman, P., 2004. Comparative international diffusion: Patterns, determinants and policies. Economics of Innovation and New Technology13 (3), 279-298.

Coase, R., 1960. The problem of social cost. Journal of Law and Economics 3, 1-44.

Dale, L., Milborrow, D., Slark, R., Strbac, G., 2004. Total cost estimates for large-scale wind scenarios in the UK. Energy Policy 32, 1949-1956. 
Davies, S., 1979. The Diffusion of Process Innovations. Cambridge University Press, Cambridge

Diaz-Rainey, I., 2008. Energy Policy and the Take-up of Green Energy Innovations: Three Empirical Studies on Induced Diffusion. PhD Thesis, Norwich Business School, University of East Anglia, UK.

Dixon, R., 1980. Hybrid Corn Revisited. Econometrica 48 (6) 1451-1461.

DTI, 2003. Energy White Paper; Our Energy Future - Creating a Low Carbon Economy. Department of Trade and Industry, February, TSO, London.

EU Commission, 2008. The support of electricity from renewable energy sources. Commission Staff Working Document, SEC (2008) 57.

EWEA, 2003. Wind energy: The facts, an analysis of wind energy in the EU25. European Wind Energy Association, Brussels.

EWEA, 2009a. Wind energy - The Facts. European Wind Energy Association, March, Brussels.

EWEA, 2009b. Pure Power - Wind energy targets for 2020 and 2030. European Wind Energy Association, March, Brussels.

Griliches, Z., 1957. Hybrid Corn: An Exploration in the Economics of Technological Change. Econometrica 25 (4), 501-522.

Griliches, Z., 1980. Hybrid Corn Revisited: A Reply. Econometrica 48 (6), 1463-1465.

GWEC, 2009. Global Wind 2008 Report, Global Wind Energy Council, April, Brussels.

Harrison, L., Milborrow, D., 2001. Illuminating the bar room. WindPower Monthly, July [online] (cited 14 October 2004) Available from $<$ http://windpower-monthly.com>.

Jaffe, AB., Newell, RG., Stavins, RN., 2002. Environmental policy and technological change. Environmental and Resource Economics 22, 4169.

Junginger, M., Faaij, A., Turkenburg, W., 2005. Global experience curves for wind farms. Energy Policy 33 (2), 133-150. 
Kildegaard, A., 2008. Green certificate markets, the risk of over-investment, and the role of long-term contracts. Energy Policy 36 (9), 3413-3421.

Lekvall, P., Wahlbin, C., 1973. A study of some assumptions underlying innovation diffusion functions. Swedish Journal of Economics 75 (4), 362-377.

Lissoni, F., Metcalfe, JS., 1994. Diffusion of innovations ancient and modern: A review of the main themes, in Dodgson, M. and Rothwell, R., (eds.), Handbook of Industrial Innovation, Elgar, Cheltenham, UK, pp.106141.

McDonald, A., Schrattenholzer, L., 2001. Learning rates for energy technologies. Energy Policy 29 (4), 255-261.

Montalvo, C., Kemp, R., 2008. Diffusion of cleaner technologies: Modeling, case studies and policy. Journal of Cleaner Production 16 (S1), S1-S6.

Neuhoff, K., 2005. Large-Scale Deployment of Renewables for Electricity Generation. Oxford Review of Economic Policy 21(1), 88-110.

Norberg-Bohm, V., 2000. Creating Incentives for Environmentally Enhancing Technological Change: Lessons From 30 Years of U.S. Energy Technology Policy. Technological Forecasting and Social Change 65 (2), 125-148.

Poznanski, K., 1983. International diffusion of steel technologies: Time lag and speed of diffusion. Technological Forecasting and Social Change 23, 305-323.

Rogers, EM., 1995. Diffusion of Innovations (4th ed.), The Free Press, New York.

Soderholm, P., Klaassen, G., 2007. Wind power in Europe: A simultaneous innovation-diffusion model. Environmental and Resource Economics 36, 163-190.

Sørensen, B., Meibom, P., 1999. Can wind power be sold in a deregulated electricity market? Proceedings of the 1999 European Wind Energy Conference, 1-5 March 1999, Nice, France pp.375-378. 
Stoneman, P., 2002. The Economics of Technological Diffusion, Blackwell Publishers Ltd, Oxford, UK.

UCS, 2004. Renewable Energy Tax Credit Saved Once Again, but BoomBust Cycle in Wind Industry Continues. Union of Concerned Scientists [online] (cited 1 February 2005) Available from $<$ http://www.ucsusa.org $>$. 